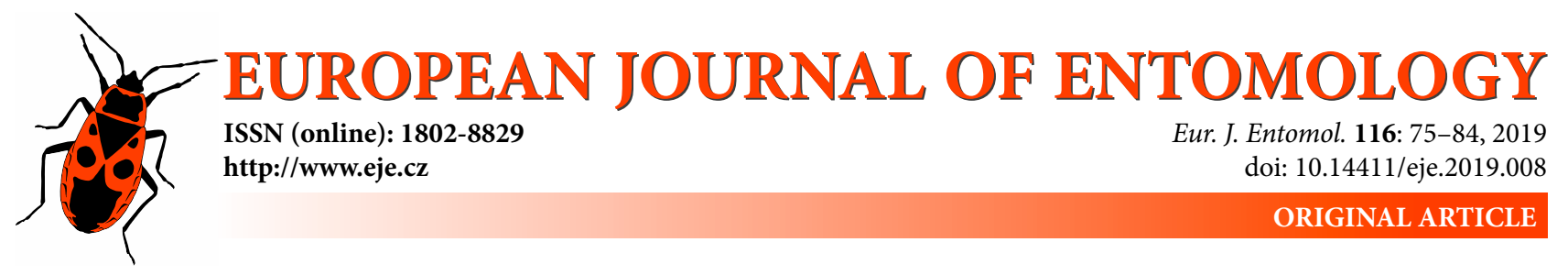

\title{
The role of larval substrate specialization and female oviposition in mediating species diversity of closely-related sepsid flies (Diptera: Sepsidae)
}

\author{
Amelie LaUX, Alexandra Wegmann, Jeannine ROY, Natalia GoURgoulianNi, Wolf U. BlanCKENHORN* \\ and PATRICK T. ROHNER
}

Department of Evolutionary Biology \& Environmental Studies, University of Zurich, Winterthurerstrasse 190, CH-8057 Zürich, Switzerland; e-mails: feliden@web.de, alexandra.wegmann@ieu.uzh.ch, natalia.gourgoulianni@ieu.uzh.ch, j.roy@gmx.ch, wolf.blanckenhorn@ieu.uzh.ch, patrick.rohner@uzh.ch

Key words. Diptera, Sepsidae, coexistence, competition, dung, ecology, food niche, sepsid dung flies, thermal niche

\begin{abstract}
Coprophagous insect communities play a critical role in the decomposition of vertebrate dung and provide ecosystem functions fundamental to modern agriculture. While the ecology of dung beetles is rather well understood, niche differentiation in coprophagous flies is poorly studied. Sepsid flies (Diptera: Sepsidae) are a vital part of the European community of coprophages, with 6-7 widespread species of Sepsis often found co-occurring in the same pasture. To advance our ecological understanding of the mechanisms that enable species to coexist, we investigated the oviposition preferences and larval performance of 7 common species of Sepsis in the dung of different large domestic and wild mammals. Substrate preferences and subsequent performance of larvae in laboratory experiments did not vary greatly. All species did very well on cow dung, the most common substrate in Central Europe, but also on dung of horse and wild boar. In contrast, flies did not prefer or grow well in dung of red and roe deer, two of the most common wild vertebrates. Thus there were only minor differences among the species tested along the specialistgeneralist (dung) gradient, indicating that differences in the choice of oviposition sites by the adults of the different fly species and larval performance do not constitute a major axis of ecological differentiation. Nevertheless, there was a positive correlation between substrate choice and larval performance indicating the preference of gravid females for particular oviposition sites is adaptive. We conclude that sepsids are common in Europe because they are well adapted to the dung of herbivorous livestock rather than wild animals. Nevertheless, specialization on particular types of dung does not define the niche of Sepsis dung flies and hence plays a minor role in mediating their species diversity.
\end{abstract}

\section{INTRODUCTION}

According to the principle of competitive exclusion, species that inhabit identical or very similar ecological niches should not be able to coexist. Hence, species that are dependent on the same physiologically non-substitutable resource are expected to only co-occur if they manage somehow to evade direct competition (Holt, 2009). Such niche differentiation can therefore be explained as an evolutionary result of competitive divergence by which competition for the same resource leads to ecological character displacement, niche shifts and eventual competitive exclusion of one species by another (Abrams, 1987). Of course, this ghost of evolution past typically cannot be retrospectively demonstrated in any particular existing community. Instead, in practice, niche differentiation is inferred post-hoc by comparing closely related species that do, or do not, coexist in space or time. This typically starts with an assessment of the spatio-temporal distribution of organisms belonging to a particular guild in nature (e.g.
Zuo et al., 2011; Loboda et al., 2018). In such work, the abstract concept of a species' ecological niche needs to be operationalized with regard to specific key environmental factors (food, temperature, phenology, etc.) that can be phenomenologically assessed (e.g. via global distribution data reflecting the climatic niche of a given species' habitat; e.g. Phillimore et al., 2012; Ståhlhandske et al., 2017) or experimentally investigated (e.g. via laboratory studies of a species' thermal niche; Angilletta, 2009). The latter involves systematic assessment of life history or fitness traits (survival, fecundity, body size, growth rate, development time, etc.) in response to the putative environmental factor in question (temperature, food quality, etc.). Subsequently, experiments that directly address currently operating competition between species, and hence competitive exclusion, can be conducted (Pacala \& Roughgarden, 1985; Fox, 2002; Levine \& HilleRisLambers, 2009; Violle et al., 2011; Germain et al., 2016).

\footnotetext{
* Corresponding author; e-mail: wolf.blanckenhorn@ieu.uzh.ch
} 
Niche differentiation is intrinsically multidimensional and often includes a plethora of biotic and abiotic components. Despite the multifaceted nature of the ecology of a species, niche differentiation (or ecological character displacement) in relation to resource use is probably one of the most common ways by which diversity is increased (e.g. Schluter et al., 1985), and is repeatedly found in parasites, pollinators and herbivorous insects (Farrell \& Mitter, 1990; Ronquist \& Liljeblad, 2001; Zuo et al., 2011). Physiological adaptations that allow for efficient nutrient acquisition are often seen as the main drivers of niche differentiation. At least in species whose immatures are poor dispersers, choice of oviposition site by the mothers plays an additional major role. It has often been proposed that female's choice of oviposition site should evolve to maximize larval performance, though the interplay between these two factors is complex (Wiklund, 1975; Fox \& Czesak, 2000; Forister, 2004; Gómez Jiménez et al., 2014; Konig et al., 2016), as other factors, such as e.g. optimal foraging by gravid females (Forister et al., 2009), can lead to different and sometimes suboptimal outcomes.

Coprophagous insect communities play a critical role in the decomposition of vertebrate dung, and as such provide early case studies of ecological community structure and species interactions (Hammer, 1941; Hanski \& Cambefort, 1991; Skidmore, 1991; Lumaret et al., 1992, 1993; Jay-Robert et al., 1997; Kadiri et al., 1997). Effective dung decomposition is crucial for nutrient cycling, and consequently of ecological and economic importance in (managed) agricultural grasslands with high cattle densities as are common throughout Central Europe. Previous studies demonstrate complex spatio-temporal patterning and rapid succession of species in cow dung (Hammer, 1941; Hanski \& Cambefort, 1991; Jay-Robert et al., 1997; Kadiri et al., 1997; Rohner et al., 2015; Sladecek et al., 2017). However, whereas dung beetles are relatively well studied (Hanski \& Cambefort, 1991; Lumaret et al., 1992, 1993; Bertone et al., 2005; Lee \& Wall, 2008), coprophagous dipteran communities are not well researched even though more than 250 central European fly species depend on decaying organic matter for their reproduction and larval development (Hammer, 1941; Hanski \& Cambefort, 1991; Skidmore, 1991; Papp, 1992; Rohner et al., 2015; Jochmann \& Blanckenhorn, 2016).

Black scavenger or dung flies (Diptera: Sepsidae) are common worldwide (Ozerov, 2005). This group generally depends on decaying organic matter for reproduction and larval development. Thus, together with various dung beetles, which tend to be much larger on average but not as numerous, and other fly groups, sepsid flies are part of most if not all coprophagous insect communities in natural and human-influenced agricultural grasslands across the globe (see e.g. Hammer, 1941; Skidmore, 1991; Blanckenhorn et al., 2016; Floate et al., 2016; Jochmann et al., 2016). Though developing in a broad range of substrates (rotting plant matter, carcasses, sewage, etc.), sepsids are reported to be more or less specialized on particular livestock faeces (Pont \& Meier, 2002). Nevertheless, several widespread species of Sepsis with apparently very similar ecological niches coexist in Europe (Pont \& Meier, 2002; Rohner et al., 2015; Rohner \& Bächli, 2016). For example, all 12 species of Sepsis reported in Switzerland (Haenni, 1998; Rohner et al., 2015) were found in a single temporal sample from one high-altitude pasture in Lenzerheide, Switzerland, by Rohner et al. (2014). Even though past research assumes that such coexistence of closely related, ecologically similar sepsid flies must result at least in part from specialization in terms of their breeding substrate, i.e. dung quality (Püchel, 1993; Pont \& Meier, 2002), there are hardly any experimental studies that have tested this hypothesis. So the precise causes of the ecological niche differentiation of such a large number of sympatric species remain puzzling and rudimentary at the local, regional and even global scales.

Here we investigate niche differentiation in oviposition preference and larval performance in relation to different kinds of breeding substrates of a number of species of Sepsis that commonly co-occur throughout Europe, the first systematic experimental investigation of its kind. While it is known that most Sepsis spp. can breed successfully in cow dung, there are many other types of livestock and wild mammal dung available in agricultural areas and forests that are at least occasionally visited and used as breeding substrates by adult sepsids (Pont \& Meier, 2002). The precise composition of dung (i.e. larval food) in terms of bacteria and fungi, as well as its consistency, dryness, particle size and specific nutrients is likely essential for larval growth, development and survival (i.e. fitness; e.g. Lumaret, 1995), and might lead to niche differentiation between species. We offered 6 common types of dung (boar, cow, horse, red deer, roe deer, sheep) to 7 species of Sepsis in the laboratory in order to assess, (1) the dung preference of ovipositing females in a choice experiment, and (2) the survival, development time, growth rate and final body size of flies that developed in each type of dung. If differential resource use facilitates the evasion of competition and hence enables co-occurrence, we expected larvae to be specialized on different types of dung (or particle sizes, nutrient contents, etc.), and this should be reflected in both larval performance and oviposition choice. If the choice of oviposition sites by gravid females is adaptive, we also expected a positive correlation between female oviposition preference and larval survival in the different types of dung.

\section{MATERIALS AND METHODS}

\section{Species, dung collection and general rearing methods}

We investigated several species that commonly co-occur in Europe (S. cynipsea, S. fulgens, S. neocynispea, S. orthocnemis, S. punctum, S. thoracica), along with North American S. punctum (Ottawa, Ontario, Canada) and $S$. neocynipsea (Belgrade, Montana, USA), and $S$. lateralis from Tenerife (La Laguna, Canary Islands, Spain) for direct comparison. We therefore used 9 evolutionary independent lineages that we refer to as "species" or "taxa" for simplicity (note that continental populations of $S$. punctum and $S$. neocynipsea differ markedly in behaviour, mating system and morphology: Dmitriew \& Blanckenhorn, 2012; 
S. cynipsea

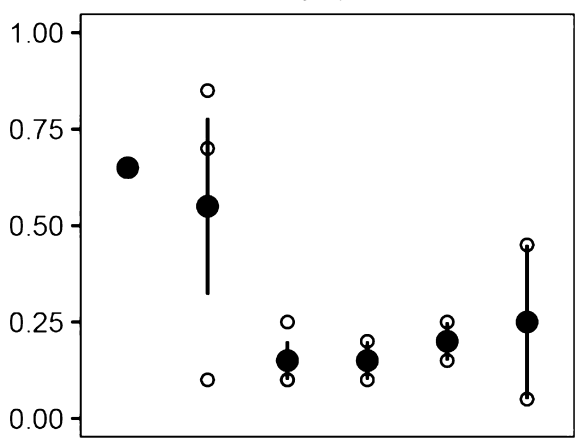

S. neocynipsea Montana
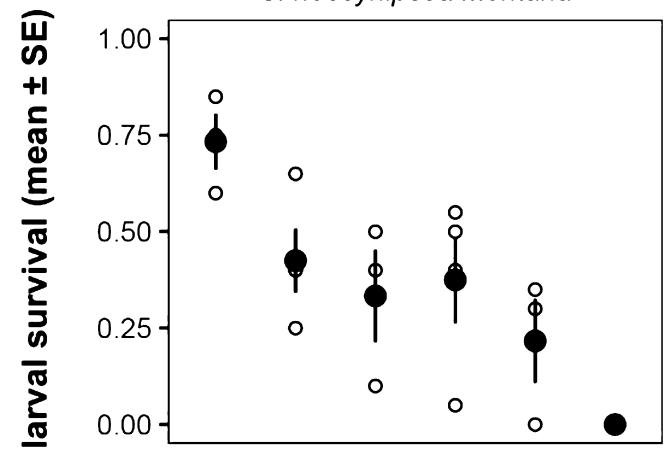

S. punctum Ottawa

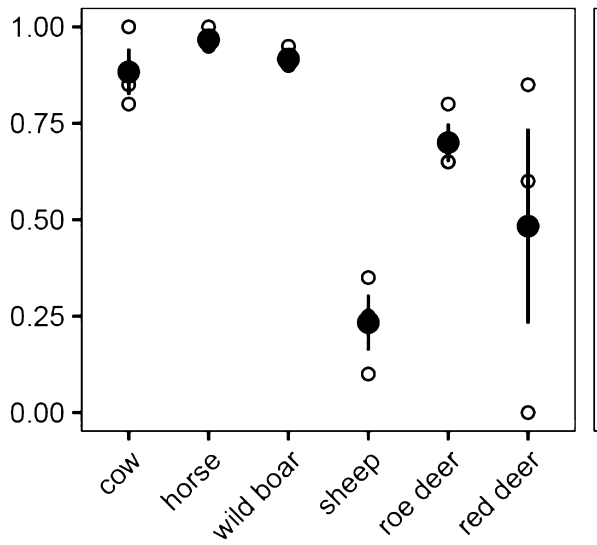

S. fulgens

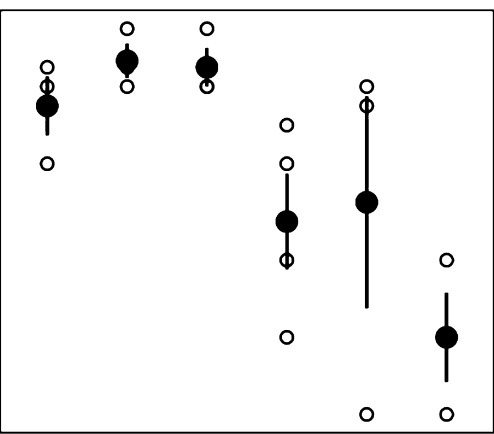

S. neocynipsea Sörenberg

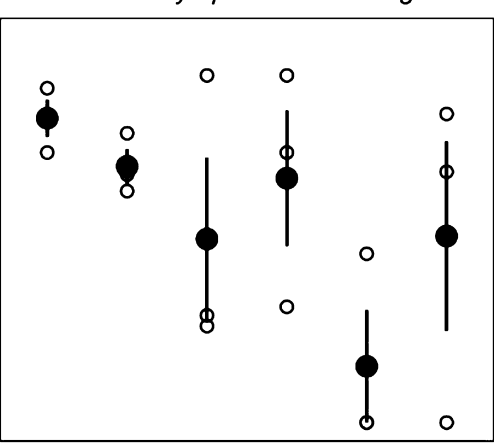

S. punctum Zürich

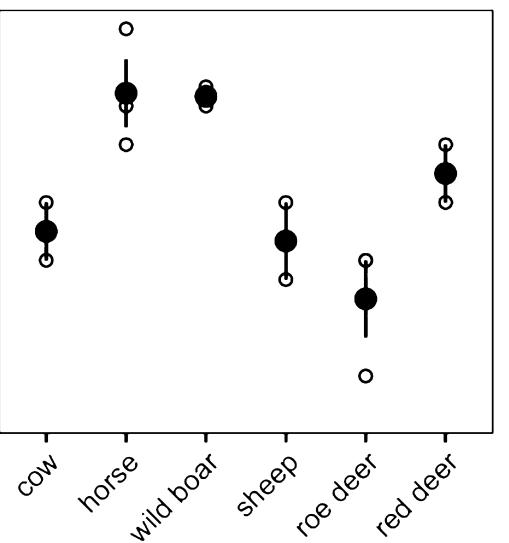

S. lateralis

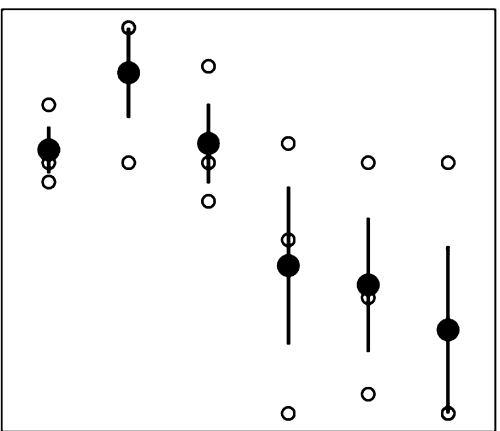

S. orthocnemis

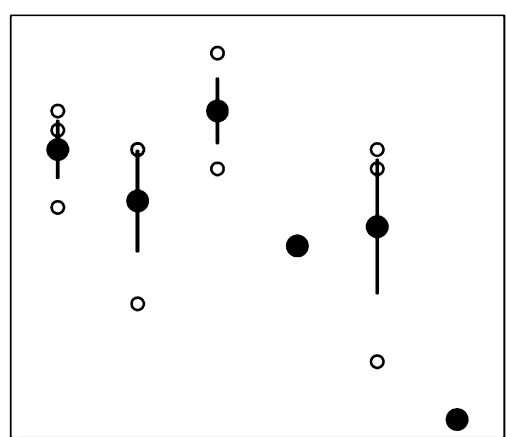

S. thoracica

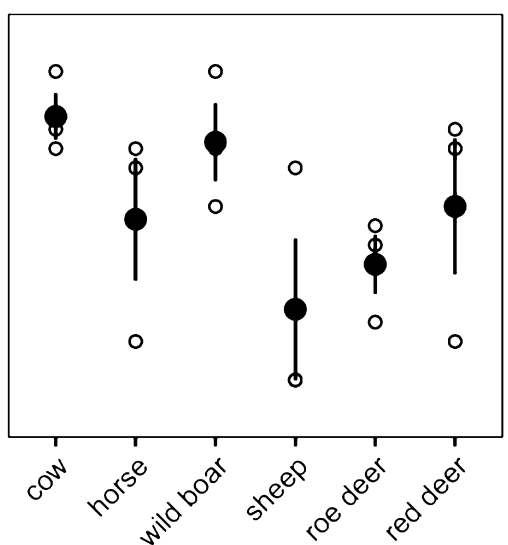

dung type

Fig. 1. Mean probability (filled circles) \pm SE of egg-to-adult survival of larvae of 9 (sub)species of Sepsis developing in 6 types of vertebrate dung (open circles denote the full range of the 3 replicates; species: $\mathrm{P}=0.002$; type of dung and interaction: $\mathrm{P}<0.001$ ).

Puniamoorthy et al., 2012; Rohner et al., 2016; Giesen et al., 2017; Rohner \& Blanckenhorn, 2018). The Central European individuals tested came from standard cultures of all species originally collected around Schwamendingen, Zurich, Switzerland (47.34N, 8.54E; ca. $450 \mathrm{~m}$ altitude), except for S. neocynipsea, which came from nearby Sörenberg, Switzerland (46.87N, 8.27E; ca. $1150 \mathrm{~m}$ ), as it is rare in the lowlands. Using standard rearing methods, at least two replicated cultures were available per species consisting of ca. 200 adult flies kept in 3-liter $(2.2 \times 1.2 \times 1.2$ $\mathrm{dm}^{3}$ ) plastic containers supplied with sugar, water, and cow dung ad libitum at constant $18^{\circ} \mathrm{C}, 60 \%$ r.h., and $14 \mathrm{~h}$ light.

We used dung from 6 large wild and livestock mammals common in Switzerland: wild boar, cow, horse, red deer, roe deer and sheep. Cow and sheep dung was collected from nearby farms; all other dung from wild animal parks (cow: cattle farm in Schwamendingen, Zurich; sheep: Institute for Animal Nutrition of the University of Zurich; horse: Wildpark Langenberg; boar, roe deer, red deer: Tierpark Goldau). In all cases, freshly collected dung from many individuals was mixed thoroughly and subsequently frozen at $-80^{\circ} \mathrm{C}$ for at least 2 weeks to kill all arthropods. After defrosting, we measured the water content of all the different types of dung thrice by weighing the dung before and after drying for $48 \mathrm{~h}$ at $60^{\circ} \mathrm{C}$.

\section{Larval performance}

To obtain test individuals of a given species for the experiment, small dishes with fresh cow dung were placed inside their standard laboratory cultures for $24 \mathrm{~h}$ for females to lay eggs. This dish was subsequently removed and stored at $24^{\circ} \mathrm{C}$ for 48 $\mathrm{h}$ until larvae hatched and had reached the second instar (following Ferrar, 1987) and were large enough to be handled. 20 larvae per species/dung replicate were then transferred with a fine brush into rectangular dishes $\left(44 \times 22 \times 16 \mathrm{~mm}^{3}\right)$ filled with dung (approximately same volume and weight for all types of dung), 
A
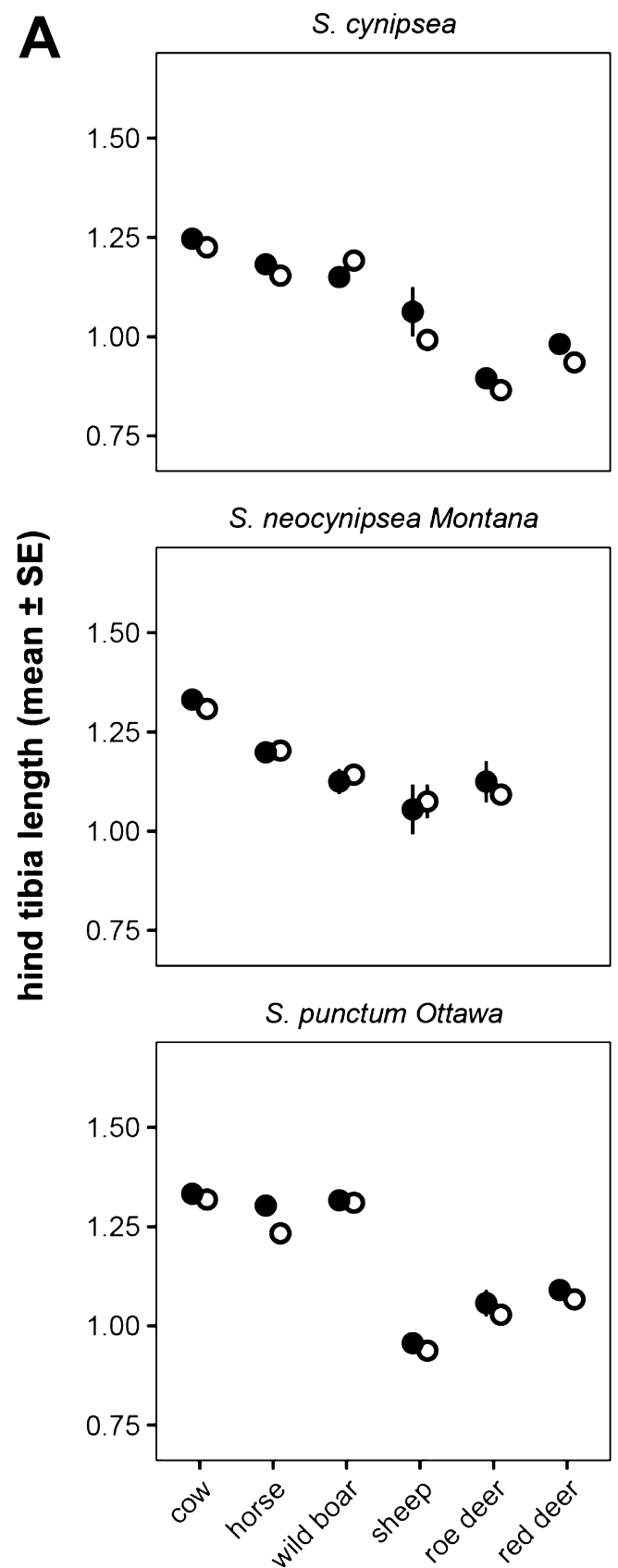

S. fulgens

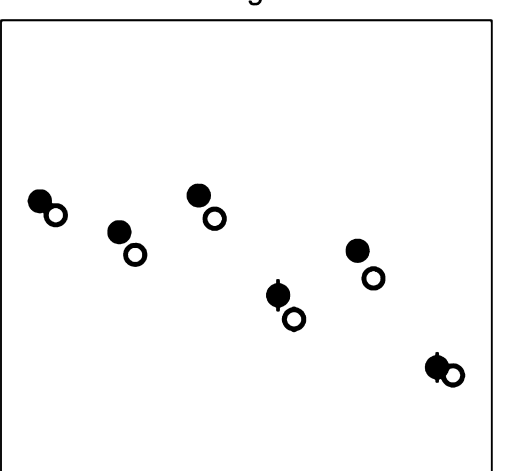

S. neocynipsea Sörenberg

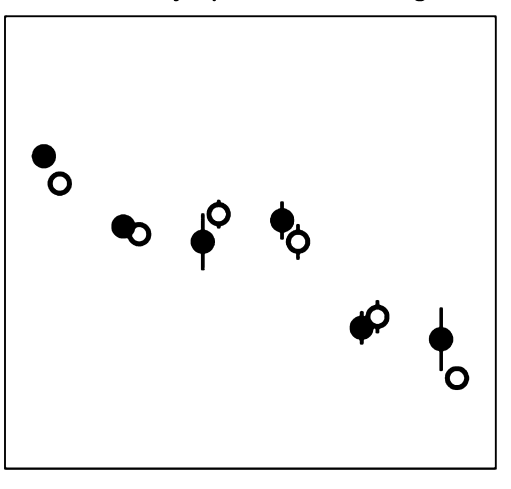

S. punctum Zürich

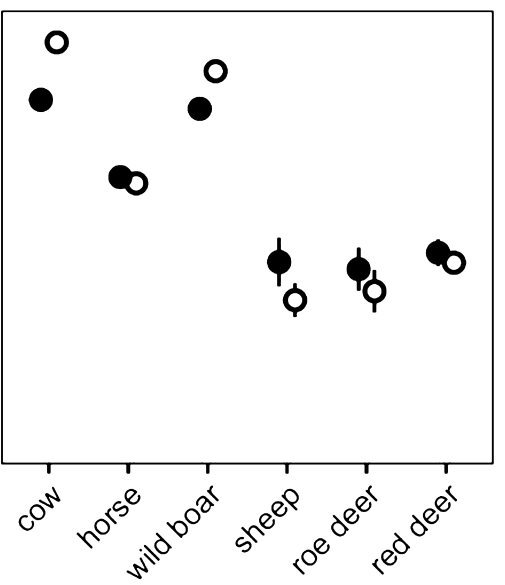

dung type
S. lateralis

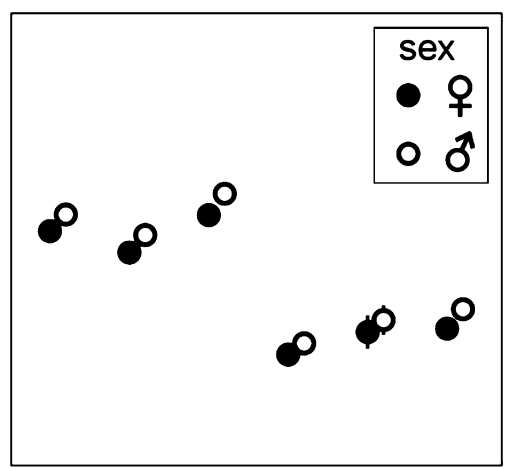

S. orthocnemis

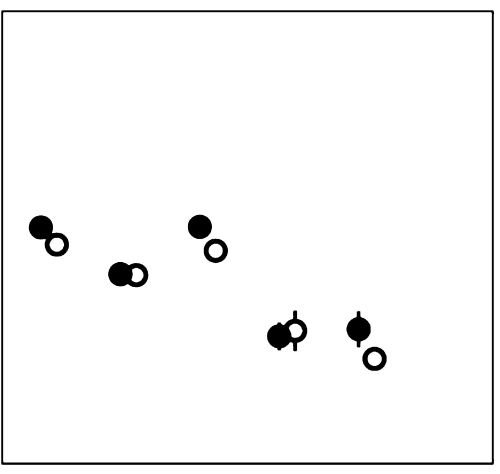

S. thoracica

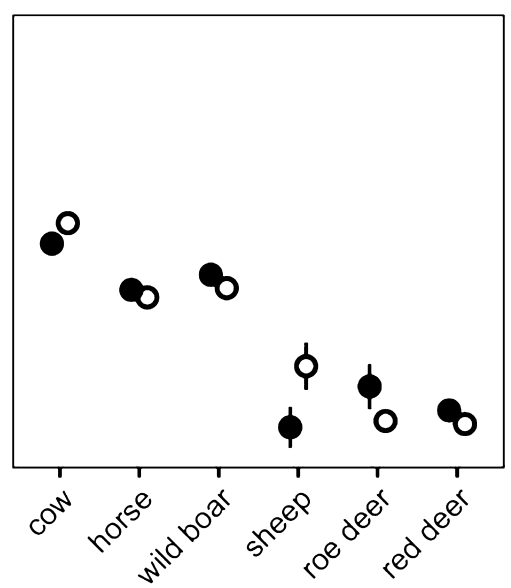

Fig. 2. Mean length of hind tibia (in $\mathrm{mm} ; \mathrm{A}$ ) and egg-to-adult development time (in days; B, see next page) \pm SE of larvae of 9 (sub)species of Sepsis developing in 6 types of vertebrate dung.

which were individually held in glass vials lined with filter paper at $24^{\circ} \mathrm{C}$. We scored survivorship as the proportion of individuals that emerged, their sex-specific (egg-to-adult) development time and measured the length of their hind tibia as a reliable index of body size. A rough linearized growth rate was calculated as hind tibia length divided by development time (in days). We thus had a 7 (9) species by 6 dung types (by 2 sexes) design, each combination replicated 3 times (with experimental dish as random effect because several individuals of both sexes emerged from each). Non-significant interactions were removed.

To quantify and compare the degree of specialization among species, we used the larva-to-adult survival data and calculated various diversity indices that indicate how well a species deals with the different types of dung. For each replicate, we calcu- lated (i) the total number of individuals per species that emerged from each type of dung (akin to species richness), (ii) evenness, which quantifies the variation in the proportions of individuals that emerged from the different types of dung, and (iii) the Shannon-diversity index. ANOVAs were used to test for differences in these diversity indices among species.

\section{Adult oviposition preference}

Using the same species and types of dung as above, we conducted a second experiment to determine the oviposition preferences of females of a given species when simultaneously offered all types of dung (following Blanckenhorn et al., 2013). Small rectangular dishes $\left(44 \times 22 \times 6 \mathrm{~mm}^{3}\right)$ filled with dung of each kind were simultaneously introduced in a randomized spatial 


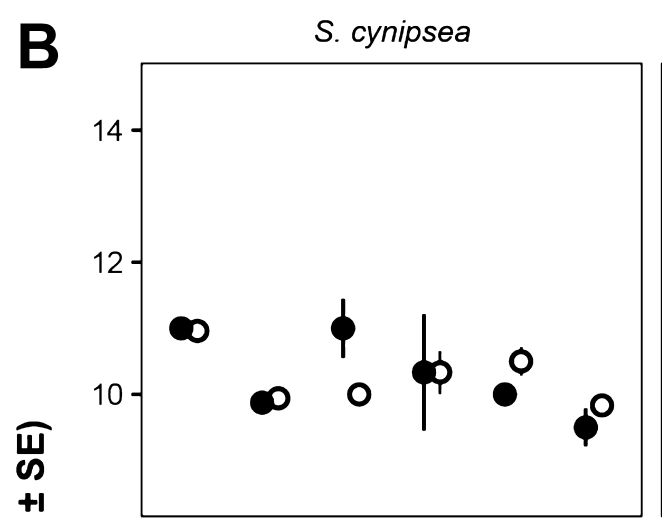

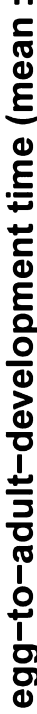

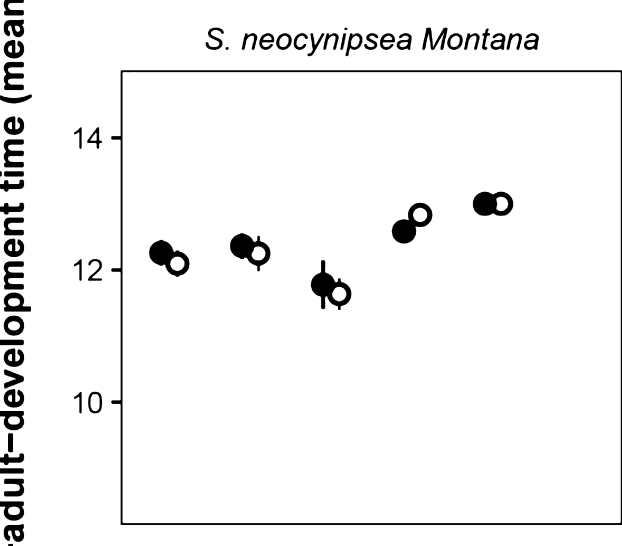

S. punctum Ottawa

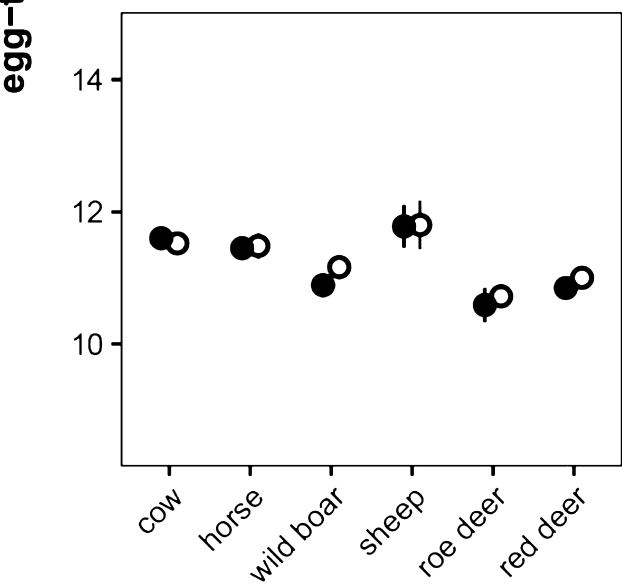

S. fulgens

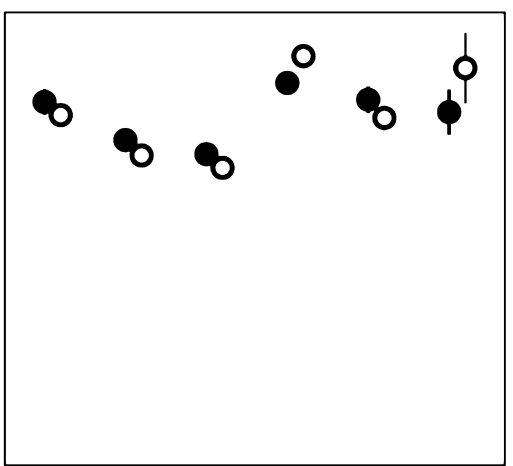

S. neocynipsea Sörenberg

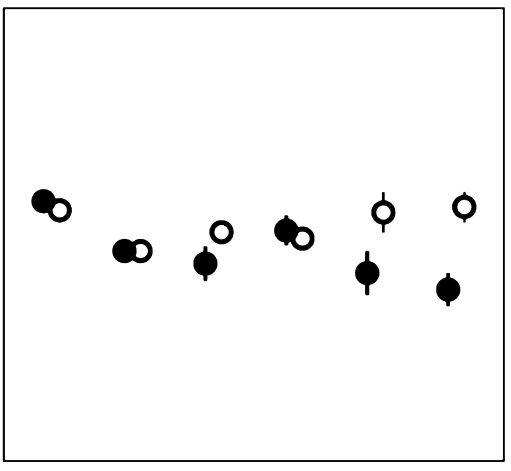

S. punctum Zürich

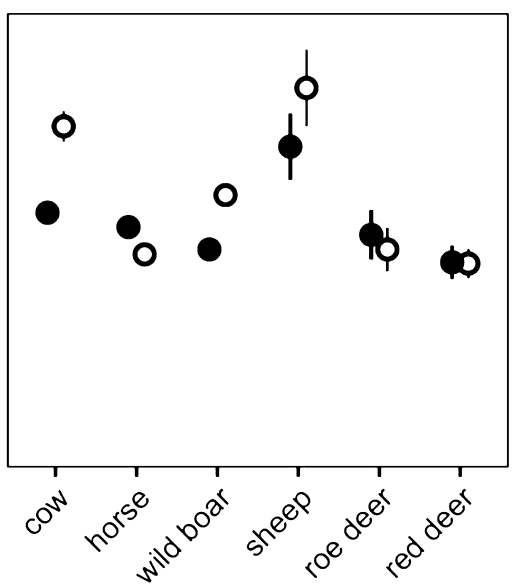

S. lateralis

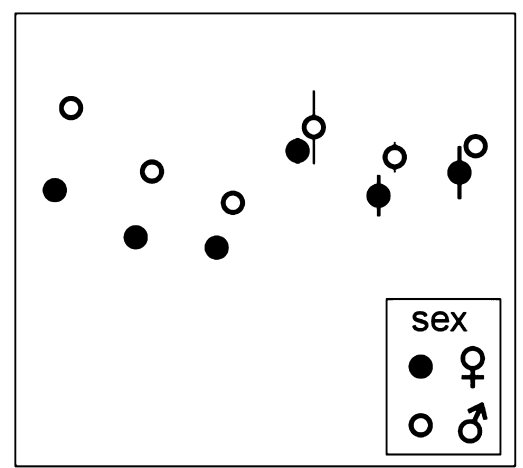

S. orthocnemis

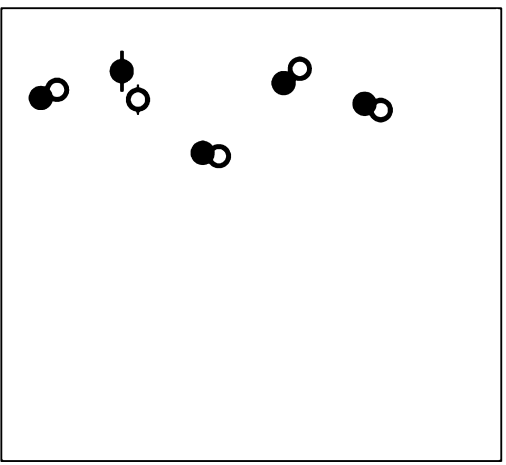

S. thoracica

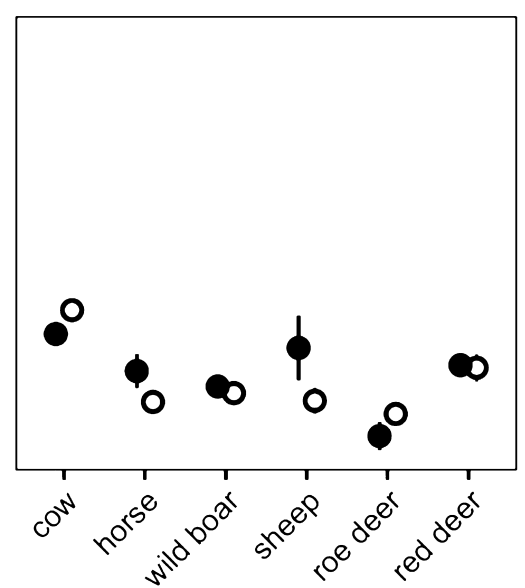

dung type

Fig. 2 (continued).

array into the above-described 3-litre population containers containing many individuals of each species (at $18^{\circ} \mathrm{C}$ ). After $24 \mathrm{~h}$, all eggs laid were counted. There were three (container) replicates per species / population.

\section{RESULTS}

\section{Larval performance}

Larva-to-adult survival of species varied significantly in the different types of dung $(\mathrm{P}=0.002$; dung and taxa by dung interaction: $\mathrm{P}<0.001)$. Survival in deer dung and sheep dung was generally poor for all taxa. By contrast, survival in dung of cattle, horse and wild boar was high, except for S. cynipsea, which also survived poorly in wild boar dung (Fig. 1). Correspondingly, the adult flies that emerged, after roughly the same egg-to-adult development time, from red and roe deer and sheep dung tended to be smaller, implying slower larval growth (Fig. 2; Table 1). The different species varied in their performance in the different types of dung (significant species by dung interaction in Table 1). While Shannon index and richness based on larval survival did not differ among species $\left(\mathrm{F}_{8,17}=1.74\right.$, $\mathrm{P}=0.161 ; \mathrm{F}_{8,17}=1.46, \mathrm{P}=0.243$, respectively), there was interspecific variation in evenness $\left(\mathrm{F}_{8,17}=3.16 \mathrm{P}=0.022\right.$; Fig. 4). 
S. cynipsea

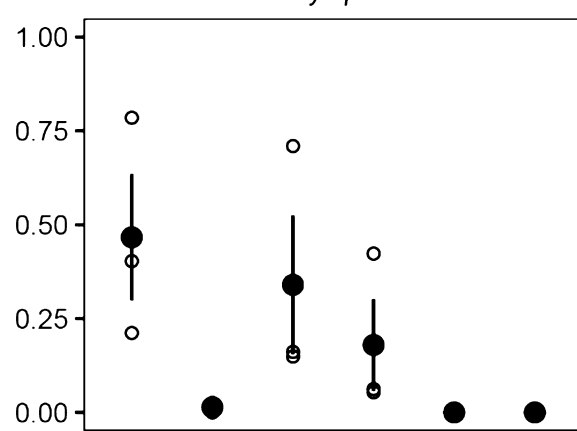

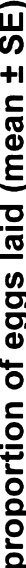

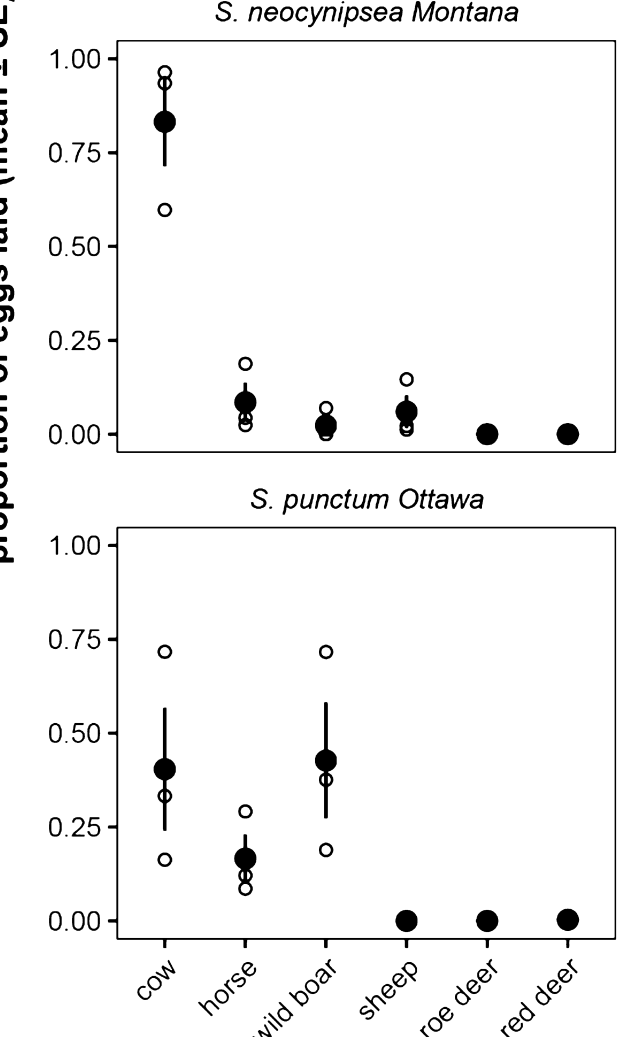

S. fulgens

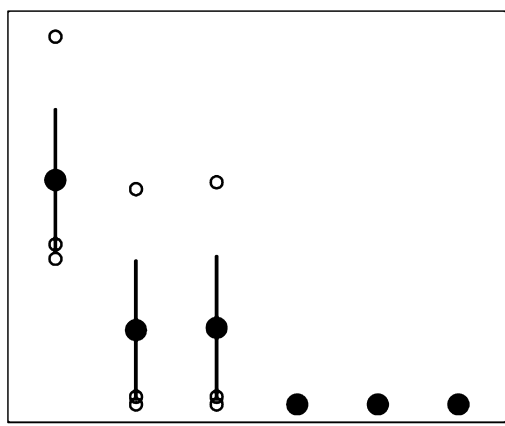

S. neocynipsea Sörenberg

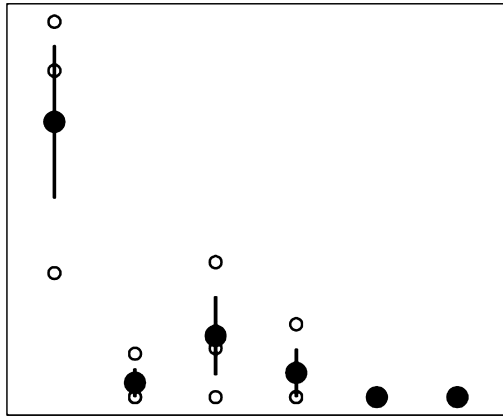

S. punctum Zürich

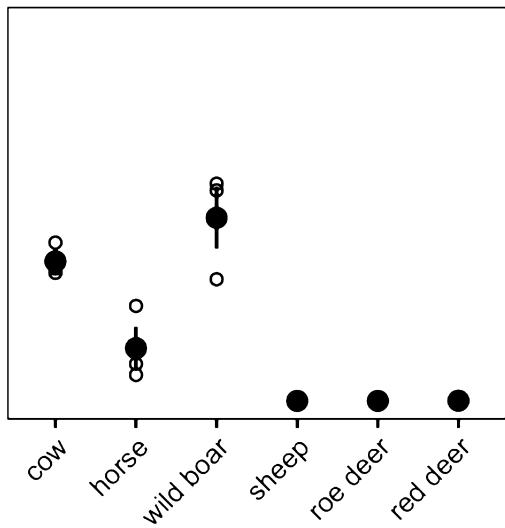

S. lateralis

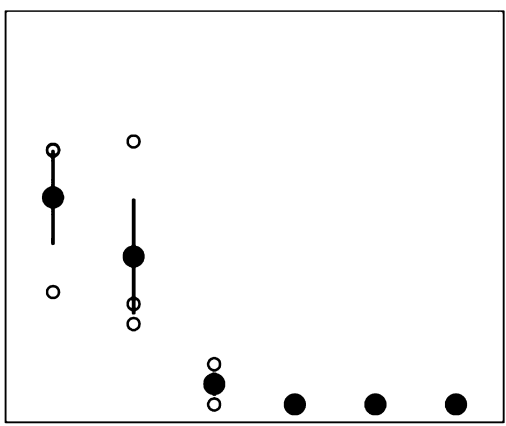

S. orthocnemis

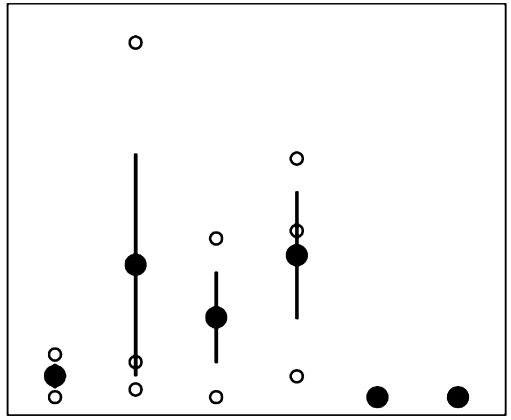

S. thoracica

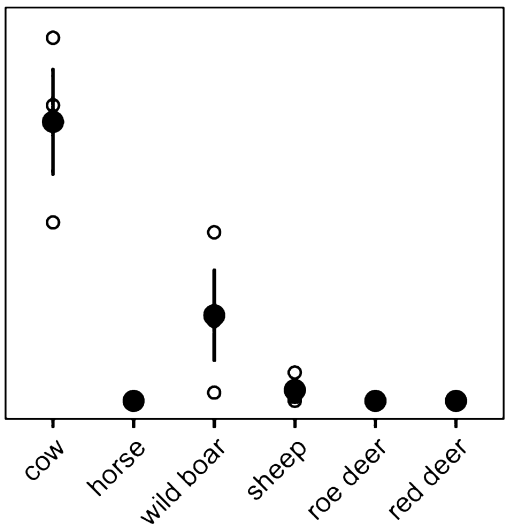

dung type

Fig. 3. Mean proportion (filled circles) \pm SE of the eggs laid by females of 9 (sub)species of Sepsis into 6 types of vertebrate dung offered simultaneously as oviposition substrates (open circles denote the full range of the 3 replicates; species, type of dung and interaction: $P$ $<0.001)$.

The proportion of water $( \pm \mathrm{SE})$ in the different types of dung was estimated as: $0.81( \pm 0.001)$ for that of cow, 0.77 $( \pm 0.013)$ for horse, $0.69( \pm 0.007)$ for red deer, $0.72( \pm$ $0.001)$ for roe deer, $0.78( \pm 0.003)$ for sheep and $0.71( \pm$ $0.003)$ for wild boar $(\mathrm{P}<0.01)$.

\section{Adult oviposition preference}

In accordance with the results of the performance test, most species of sepsid flies preferred cattle, horse and wild boar dung over deer and sheep dung (Fig. 3), so there was a positive correlation between performance and oviposition preference (Fig. 5). In fact, no eggs whatsoever were laid

Table 1. Analysis of variance of the effects of 6 types of dung, 9 taxa and sex (plus their interactions; excluded if not significant) on the length of the hind tibia, development time and growth rate.

\begin{tabular}{|c|c|c|c|c|c|c|c|c|c|c|c|c|}
\hline & \multicolumn{4}{|c|}{ Length of hind tibia } & \multicolumn{4}{|c|}{ Development time } & \multicolumn{4}{|c|}{ Growth rate } \\
\hline & MS & df & $F$ & $\mathrm{P}$ & MS & $\mathrm{df}$ & $\mathrm{F}$ & $\mathrm{P}$ & MS & df & $\mathrm{F}$ & $\mathrm{P}$ \\
\hline Species & 0.967 & 8 & 58.69 & $<0.001$ & 129.341 & 8 & 120.25 & $<0.001$ & 0.011 & 8 & 50.05 & $<0.001$ \\
\hline Type of dung & 3.287 & 5 & 185.62 & $<0.001$ & 22.892 & 5 & 18.95 & $<0.001$ & 0.021 & 5 & 92.68 & $<0.001$ \\
\hline Sex & 0.029 & 1 & 1.63 & 0.203 & 5.771 & 2 & 6.19 & 0.002 & 0.001 & 1 & 4.78 & 0.030 \\
\hline Species * type of dung & 0.073 & 38 & 3.64 & $<0.001$ & 3.407 & 38 & 2.55 & $<0.001$ & 0.001 & 38 & 2.79 & $<0.001$ \\
\hline Species * sex & & & & n.s. & 2.674 & 9 & 2.29 & 0.018 & & & & n.s. \\
\hline
\end{tabular}




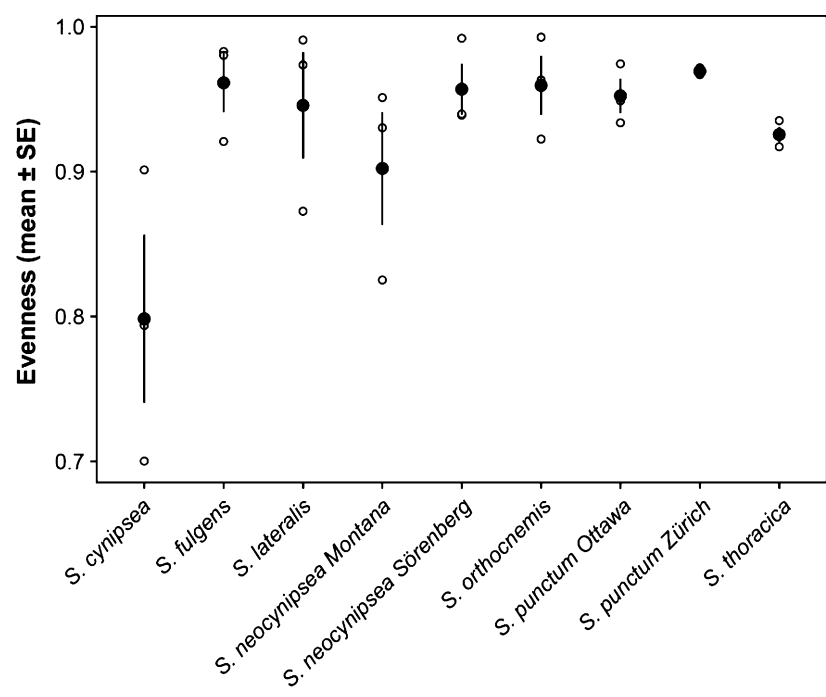

Fig. 4. Mean evenness (filled circles) \pm SE, a standard diversity index indicating the degree of specialisation, of 9 (sub)species of Sepsis flies for 6 types of vertebrate dung based on larval survival (i.e. Fig. 1; the range of the replicates for each species is indicated by the open circles).

into roe and red deer dung by any species of Sepsis (Fig. 3). Most species favoured cattle dung except $S$. orthocnemis, which favoured horse, sheep and wild boar dung even though they also performed well on cattle dung (Fig. 3 vs. Fig. 2).

While most species did well on at least cattle, but often also horse and wild boar dung (i.e. wild pigs; the three most common livestock in Europe: Figs 1,2), S. cynipsea preferred sheep (also very common) over horse, $S$. lateralis preferred horse over wild boar, $S$. thoracica the opposite, whereas $S$. neocynipsea appears to be a cattle dung specialist (Fig. 3). S. fulgens does well on both horse and wild boar (besides cattle), with $S$. orthocnemis definitely discriminating against cattle dung and preferring dung of the other livestock (Fig. 3). Based on oviposition choice, S. neocynipsea and $S$. thoracica seem most specialized on cattle dung, whereas all other species are more generalist, though the differences based on our data are not great (Fig. $3)$.

\section{DISCUSSION}

Given that diversity is often linked to ecosystem function (Oehri et al., 2017), understanding the mechanisms mediating diversity and abundance of coprophages could be vital for agricultural management. Substrate preferences of ovipositing females and performance of larvae in the laboratory did not vary greatly among 7 European species of sepsids that commonly co-occur in pastures in nature. All species did very well on cow dung, the most common substrate in Switzerland, but also on that of horse and wild boar. In contrast, flies did not grow well in dung of red and roe deer, two of the most common wild vertebrates in the area, and did not lay any eggs on it (Fig. 3). Hence, the foraging niches of the closely-related species investigated seem to overlap greatly, indicating that specialization on different kinds of dung contributes little to the avoid-

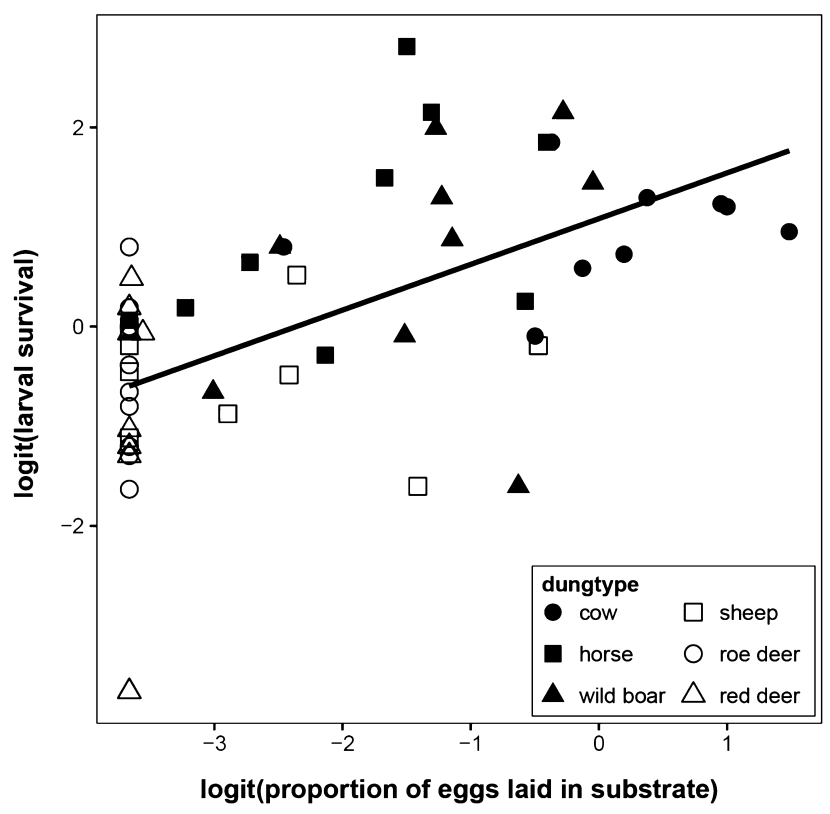

Fig. 5. Positive relationship of logit survival (from Fig. 1) and logit oviposition preference (from Fig. 3) for 9 (sub)species of Sepsis and 6 types of dung $(P<0.001)$. The oviposition prefence by species interaction was not significant, hence type of dung and species were both treated as random effects in the analysis.

ance of direct competition in the larval habitat. Despite this rather slight interspecific variation, we nevertheless found a positive correlation between a mother's choice of substrate and subsequent larval performance (i.e. survival) across the 9 taxa (Fig. 5). This follows the expectation that natural selection should align adult oviposition preference and larval performance. We conclude that Sepsis spp. are common because they are better adapted to the dung of herbivorous livestock than that of wild animals. In contrast, the type of dung does not define the niche of Sepsis dung flies, at least not in the absence of competition (as tested here). The mechanisms allowing dung insects to coexist despite direct larval competition, therefore, remain somewhat elusive.

Even though we did not find marked differences in the dung preferences of the closely-related species investigated, substrate specialization of sepsid flies is very apparent at higher phylogenetic levels. Orygma luctuosum, for instance, which is the sister taxon to all other sepsids, breeds exclusively on rotting brown algae. Zuskamira and Ortalischema are mainly collected on horse dung, and most members of the genus Themira are known to breed primarily in waterfowl (ducks, geese, swans, etc.) excrement and only rarely visit cowpats (Table 1 in Pont \& Meier, 2002). Substrate preference therefore is evidently not strongly constrained and can evolve, but appears to vary primarily among clades with little variation between very closely related species or populations.

The association between larval performance and adult oviposition behaviour is complex and has been debated in the past. Insects, for instance, are described as showing innate oviposition preferences (Dormont et al., 2010), or attracted to or ovipositing preferentially on substrates 
that they themselves fed on during their larval development (i.e. the highly-debated Hopkins host selection principle: Barron, 2001). Oviposition can further depend on the presence of other species or conspecifics (Dormont et al., 2010). However, females may also reproduce at sites that benefit themselves but not necessarily their larvae (Forister et al., 2009). Here we found females prefer those types of dung that were most suited for their offspring. This is most likely an adaptive response, even though sepsid fly females are not able to detect hazardous residues of antibiotics (Conforti et al., 2018).

Although we studied the locally most common and abundant species of sepsids and types of vertebrate dung, this study is incomplete in that there are also several more species and substrates. This is typically the case in studies of e.g. host-parasite or plant-pollinator systems, where it is often not possible to study all guild members and potential substrates. While testing the dung of several vertebrate herbivores (cow, horse, sheep, deer) and one omnivore (boar / pig), we did not test that of carnivores, even though at least $S$. punctum, for instance, is known to breed regularly in dog excrement (also a domesticated mammal: Pont \& Meier, 2002). While some sepsids are able to successfully breed in dung of various (wild or domesticated) carnivores, we doubt that many specialize on that type of dung as it is too rare. However, Meroplius minutus is putatively "particularly attracted", i.e. potentially a specialist, on human (an omnivore) faeces and is now presumably rare because of the current high level of human hygiene (van der Goot, 1987; Pont \& Meier, 2002). Testing more types of dung of many categories (omnivore, carnivore; cf. Frank et al., 2017), rotting plant material and carcasses, is therefore warranted. However, the finding that all species tested seem to perform very well on cow dung indicates these species share similar physiological foraging niches and adaptations.

Frank et al. (2017) recently assessed the nutrient quality and quantity of dung produced by various wild and domestic vertebrate herbivores, carnivores and omnivores (including some birds) and found it to be unrelated to its attractiveness for various species of dung beetles. Herbivore dung had the highest $\mathrm{C} / \mathrm{N}$ ratio and lipid content but lowest amino acid content of all dung categories. Cow dung ( $81 \%$ water, as estimated here), in fact herbivore dung in general (Frank et al., 2017), has the highest water content of all the types of dung tested. This might relate to Swiss cows feeding largely on fresh grass rather than other types of silage (e.g. corn mash, as is common in North America). It is possible that the water content, in addition to various nutritional aspects, plays some role in the flies' choice of particular type of dung for egg laying (as is the case in other flies: Fatchurochim et al., 1989). This might be of particular relevance if high water content lowers the risk of desiccation and hence prolongs the duration over which larvae can develop in the dung (Lumaret, 1995).

In conclusion, we found little variation in the preferences for different types of dung and performance of 7 (9) closely related and common dung flies. Preferences for different types of dung thus cannot account for, or define, the niche differentiation of these species that regularly co-exist in the same pastures or other sites in Switzerland and elsewhere (Rohner et al., 2014, 2015, 2019). We further found that oviposition preference of adults correlated with larval performance, indicating the oviposition behaviour of gravid fly females is adaptive. Given this association and the low interspecific variance in performance across substrates, it appears that the temperate sepsid flies tested are well adapted to or dependent on the presence of vertebrate species of livestock (rather than wild) (cf. Pont \& Meier, 2002). Although sepsids are probably among the few taxa that benefit(ed) from humanity's agricultural activities and are not of special conservation concern, our study nevertheless shows that these flies are particularly vulnerable to residues of regularly-used veterinary pharmaceuticals because of their predominant use of the dung of livestock (Blanckenhorn et al., 2013; Puniamoorthy et al., 2014; Floate et al., 2016; Jochmann et al., 2016; Conforti et al., 2018).

ACKNOWLEDGEMENTS. This work was supported by several grants from the Swiss National Science Foundation, most recently grant no. 31003A_143787.

\section{REFERENCES}

ABRAMs P.A. 1987: Alternative models of character displacement and niche shift. I. Adaptive shifts in resource use when there is competition for nutritionally nonsubstitutable resources. Evolution 41: 651-661.

Angilletta JR M.J. 2009: Thermal Adaptation: A Theoretical and Empirical Synthesis. Oxford University Press, Oxford, 302 pp.

Barron A.B. 2001: The life and death of Hopkins' host-selection principle. - J. Insect Behav. 14: 725-737.

Bertone M., Green J., Washburn S., Poore M., Sorenson C. \& WATSON D.W. 2005: Seasonal activity and species composition of dung beetles inhabiting cattle pastures in North Carolina. Ann. Entomol. Soc. Am. 98: 309-321.

Blanckenhorn W.U., Puniamoorthy N., Scheffczyk A. \& RömBKE J. 2013: Evaluation of eco-toxicological effects of the parasiticide moxidectin in comparison to ivermectin in 11 species of dung flies. - Ecotoxicol. Environ. Saf. 89: 15-20.

Blanckenhorn W.U., Rohner P.T., Bernasconi M.V., HaughaugSTETTER J. \& BUSER A. 2016: Is qualitative and quantitative metabarcoding of dung fauna biodiversity feasible? - Environ. Toxicol. Chem. 35: 1970-1977.

Conforti S., Dietrich J., Kuhn T., Van Koppenhagen N., Baur J., Rohner P.T., Blanckenhorn W.U. \& SChÄFER M.A. 2018: Comparative effects of the parasiticide ivermectin on survival and reproduction of adult sepsid flies. - Ecotoxicol. Environ. Saf. 163: 215-222.

DMitriew C. \& BLANCKenhorn W.U. 2012: The role of sexual selection and conflict in mediating among-population variation in mating strategies and sexually dimorphic traits in the black scavenger fly Sepsis punctum. - PLoS ONE 7(12): e49511, $7 \mathrm{pp}$.

Dormont L., Jay-Robert P., Bessiere J.M., Rapior S. \& Lumaret J.-P. 2010: Innate olfactory preferences in dung beetles. $-J$. Exp. Biol. 213: 3177-3186.

FARrell B. \& Mitter C. 1990: Phylogenesis of insect/plant interactions: have phyllobrotica leaf beetles (Chrysomelidae) and 
the lamiales diversified in parallel? — Evolution 44: 1389 1403.

Fatchurochim S., Geden C.J. \& Axtell R.C. 1989: Filth fly (Diptera) oviposition and larval development in poultry manure of various moisture levels. - J. Entomol. Sci. 24: 224-231.

Ferrar P. 1987: A Guide to the Breeding Habits and Immature Stages of Diptera, Cyclorrhapha. Brill, Leiden, 907 pp.

Floatke K.D., Düring R.-A., Hanafi J., Jud P., Lahr J., Lumaret J.-P., Scheffczyk A., Tixier T., Wohde M., Römbke J., SAutot L. \& BLANCKENHORN W.U. 2016: Validation of a standard test method in four countries to assess the toxicity of residues in dung of cattle treated with veterinary medical products. - Environ. Toxicol. Chem. 35: 1934-1946.

FORISTER M.L. 2004: Oviposition preference and larval performance within a diverging lineage of lycaenid butterflies. Ecol. Entomol. 29: 264-272.

Forister M.L., Nice C.C., Fordyce J.A. \& Gompert Z. 2009 Host range evolution is not driven by the optimization of larval performance: the case of Lycaeides melissa (Lepidoptera: Lycaenidae) and the colonization of alfalfa. - Oecologia 160: 551-561.

Fox J.W. 2002: Testing a simple rule for dominance in resource competition. - Am. Nat. 159: 305-319.

Fox C.W. \& CZESAK M.E. 2000: Evolutionary ecology of progeny size in arthropods. - Annu. Rev. Entomol. 45: 341-369.

Frank K., Brückner A., Hilpert A., Heethoff M. \& Bluthgen N. 2017: Nutrient quality of vertebrate dung as a diet for dung beetles. - Sci. Reports 7: 12141, 12 pp.

Germain R.M., Weir J.T. \& Gilbert B. 2016: Species coexistence: macroevolutionary relationships and the contingency of historical interactions. - Proc. R. Soc. (B) 283: 20160047, 7 pp.

Giesen A., Blanckenhorn W.U. \& Schäfer MA. 2017: Behavioural mechanisms of reproductive isolation between two hybridizing dung fly species. - Anim. Behav. 132: 155-166.

Gómez Jiménez M.I., Sarmiento C.E., Díaz M.F., Chautá A., Peraza A., Ramírez A. \& Poveda K. 2014: Oviposition, larval preference, and larval performance in two polyphagous species: does the larva know best? - Entomol. Exp. Appl. 153: 24-33.

HaennI J.-P. 1998: Sepsidae. In Merz B., Baechli G., Haenni J.-P. \& Gonseth Y. (eds): Diptera-Checklist. Fauna Helvetica. Vol. 1. Schweizerische Entomologische Gesellschaft, Neuchâtel, pp. 249-250.

HAMMER O. 1941: Biological and ecological investigations on flies associated with pasturing cattle and their excrements. Vidensk. Medd. Dansk Naturh. Foren. 105: 140-393.

Hanski I. \& Cambefort Y. 1991: Dung Beetle Ecology. Princeton University Press, Princeton, NJ, xiii +481 pp.

HoLt R.D. 2009: Bringing the Hutchinsonian niche into the 21st century: Ecological and evolutionary perspectives. - PNAS 106: 19659-19665.

JAY-ROBERT P., LOBO J.M. \& LUMARET J.-P. 1997: Altitudinal turnover and species richness variation in European montane dung beetle assemblages. - Arctic Alpine Res. 29: 196-205.

JOCHMANN R. \& BLANCKENHORN W.U. 2016: Non-target effects of Ivermectin on trophic groups of the cow dung insect community replicated across an agricultural landscape. - Basic Appl. Ecol. 17: 291-299.

Jochmann R., LipKow E. \& Blanckenhorn W.U. 2016: A field test of the effect of spiked ivermectin concentrations on the biodiversity of coprophagous dung insects in Switzerland. Environ. Toxicol. Chem. 35: 1947-1952.

Kadiri N., Lobo J.M. \& Lumaret J.-P. 1997: Conséquences de l'interaction entre préférences pour l'habitat et quantité de ressources trophiques sur les communautés d'insectes coprophages (Coleoptera: Scarabaeoidea). — Acta Oecol. 18: 107-119.

Konig M.A.E., WiKLund C. \& EhrLen J. 2016: Butterfly oviposition preference is not related to larval performance on a polyploid herb. - Ecol. Evol. 6: 2781-2789.

LEE C. \& WALL R. 2008: Distribution and abundance of insects colonizing cattle dung in South West England. - J. Nat. Hist. 40: $1167-1177$.

Levine J.M. \& HilleRisLambers J. 2009: The importance of niches for the maintenance of species diversity. - Nature 461: 254-257.

Loboda S., Savage J., Buddle C.M., Schmidt N.M. \& Høye T.T. 2018: Declining diversity and abundance of High Arctic fly assemblages over two decades of rapid climate warming. Ecography 41: 265-277.

LuMARET J.-P. 1995: Desiccation rate of excrements: a selective pressure on dung beetles. In Roy J., Aronson J. \& Di Castri F. (eds): Time Scales of Biological Responses to Water Constraints. The Case of Mediterranean Biota. SPB Academic Publishing, Amsterdam, pp. 105-118.

Lumaret J.-P., Kadiri N. \& Bertrand M. 1992: Changes in resources: Consequences for the dynamics of dung beetle communities. - J. Appl. Ecol. 29: 349-356.

Lumaret J.-P., Galante E., Lumbreras C., Mena J., Bertrand M., Bernal J.L., Cooper J.F., Kadiri N. \& Crowe D. 1993: Field effects of Ivermectin residues on dung beetles. - J. Appl. Ecol. 30: 428-436.

Oehri J., Schmid B., Schaepman-Strub G. \& Niklaus P.A. 2017: Biodiversity promotes primary productivity and growing season lengthening at the landscape scale. — PNAS 114: 10160 10165.

Ozerov A.L. 2005: World Catalogue of the Family Sepsidae (Insecta: Diptera). Zoologicheskie Issledovanii 8, Museum of Zoology, Moscow, 74 pp.

Pacala S.W. \& Roughgarden J. 1985: Population experiments with the Anolis lizards of St-Maarten and St-Eustatius. Ecology 66: 129-141.

PAPP L. 1992: Fly communities in pasture dung - Some results and problems (Diptera). - Acta Zool. Hungar. 38: 75-88.

Phillimore A.B., Stalhandske S., Smithers R.J. \& Bernard R. 2012: Dissecting the contribution of plasticity and local adaptation to the phenology of a butterfly and its host plants. - Am. Nat. 180: 655-670.

Pont A.C. \& MeIER R. 2002: The Sepsidae (Diptera) of Europe. Fauna Entomologica Scandinavica 37. Brill, Leiden, Boston, Köln, 219 pp.

PÜCHEL F. 1993: Untersuchungen über die Besiedlung von Kuhdung durch Sepsiden (Diptera). Thesis, University of Bielefeld, iv $+77 \mathrm{pp}$.

Puniamoorthy N., Blanckenhorn W.U. \& SChäFer M.A. 2012: Differential investment in pre- versus post-copulatory sexual selection reinforces a cross-continental reversal of sexual size dimorphism in Sepsis punctum (Diptera: Sepsidae). - J. Evol. Biol. 25: 2253-2263.

Puniamoorthy N., Schäfer M.A., RömbKe J., Meier R. \& BLANCKENHORN W.U. 2014: Ivermectin sensitivity is an ancient trait affecting all ecdysozoa but shows phylogenetic clustering among sepsid flies. - Evol. Appl. 7: 548-554.

RoHNER P.T. \& Bächli G. 2016: Faunistic data of Sepsidae (Diptera) from Switzerland and additional countries including the first Swiss record of Meroplius fukuharai (Iwasa, 1984). Mitt. Schweiz. Entomol. Ges. 89: 237-260. 
RoHNER P.T. \& BLANCKENHORN W.U. 2018: A comparative study of the role of sex-specific condition dependence in the evolution of sexually dimorphic traits. - Am. Nat. 192: E202-E215.

Rohner P.T., Puniamoorthy N., Ang Y., Lei Z., Blanckenhorn W.U. \& MEIER R. 2014: Genetic data confirm the species status of Sepsis nigripes, Meigen 1826 (Diptera: Sepsidae) and adds one species to the Alpine fauna while questioning the synonymy of Sepsis helvetica, Munari, 1985. — Invert. Syst. 28: $555-563$.

Rohner P.T., Bächli G., Pollini Paltrinieri L., Duelli P., Obrist M.K., Jochmann R. \& Blanckenhorn W.U. 2015: Distribution, diversity gradients and Rapoport's elevational rule in the black scavenger flies of the Swiss Alps (Diptera: Sepsidae). - Insect Conserv. 8: 367-376.

Rohner P.T., Blanckenhorn W.U. \& Puniamoorthy N. 2016: Sexual selection on male size drives the evolution of malebiased sexual size dimorphism via the prolongation of male development. - Evolution 70: 1189-1199.

Rohner P.T., Roy J., Haenni J.-P., Giesen A., Busso J.P., Schäfer M.A., PüChel-Wieling F. \& Blanckenhorn W.U. 2019: Temporal niche partitioning of Swiss black scavenger flies in relation to season and substrate age (Diptera: Sepsidae). - Alpine Entomol. 3 [in press].

RoNQUIST F. \& LILJEBLAD J. 2001: Evolution of the gall wasp-host plant association. - Evolution 55: 2503-2522.

Schluter D., Price T.D. \& Grant P.R. 1985: Ecological character displacement in Darwin's Finches. - Science 227: 1056-1059.

Skidmore P. 1991: Insects of the British Cow-dung Community, Vol. 21. Aids to Identification in Difficult Groups of Animals and Plants. Field Studies Council, Shrewsbury, $160 \mathrm{pp}$

Sladecek F.X.J., Sulakova H. \& Konvicka M. 2017: Temporal segregations in the surface community of an ephemeral habitat: Time separates the potential competitors of coprophilous Diptera. - Entomol. Sci. 20: 111-121.

StÅhlhandske S., Gotthard K. \& Leimar O. 2017: Winter chilling speeds spring development of temperate butterflies. $-J$. Anim. Ecol. 86: 718-729.

VAN DER GoOT V.S. 1987: Meroplius minutus (Wiedemann) (Dipt., Sepsidae) extinct in the low countries. - Entomol. Mon. Mag. 123: 82.

Violle C., Nemergut D.R., Pu Z.C. \& Jiang L. 2011: Phylogenetic limiting similarity and competitive exclusion. - Ecol. Lett. 14: 782-787.

WiKLUND C. 1975: The evolutionary relationship between adult oviposition preferences and larval host plant range in Papilio machaon L. - Oecologia 18: 185-197.

Zuo X.H., Guo X.G., Zhan Y.Z., Wu D., Yang Z.H., Dong W.G., Huang L.Q., Ren T.G., JiNG Y.G. \& WANG Q.H. 2011: Host selection and niche differentiation in sucking lice (Insecta: Anoplura) among small mammals in southwestern China. Parasitol. Res. 108: 1243-1251.

Received January 2, 2019; revised and accepted February 14, 2019 Published online March 1, 2019
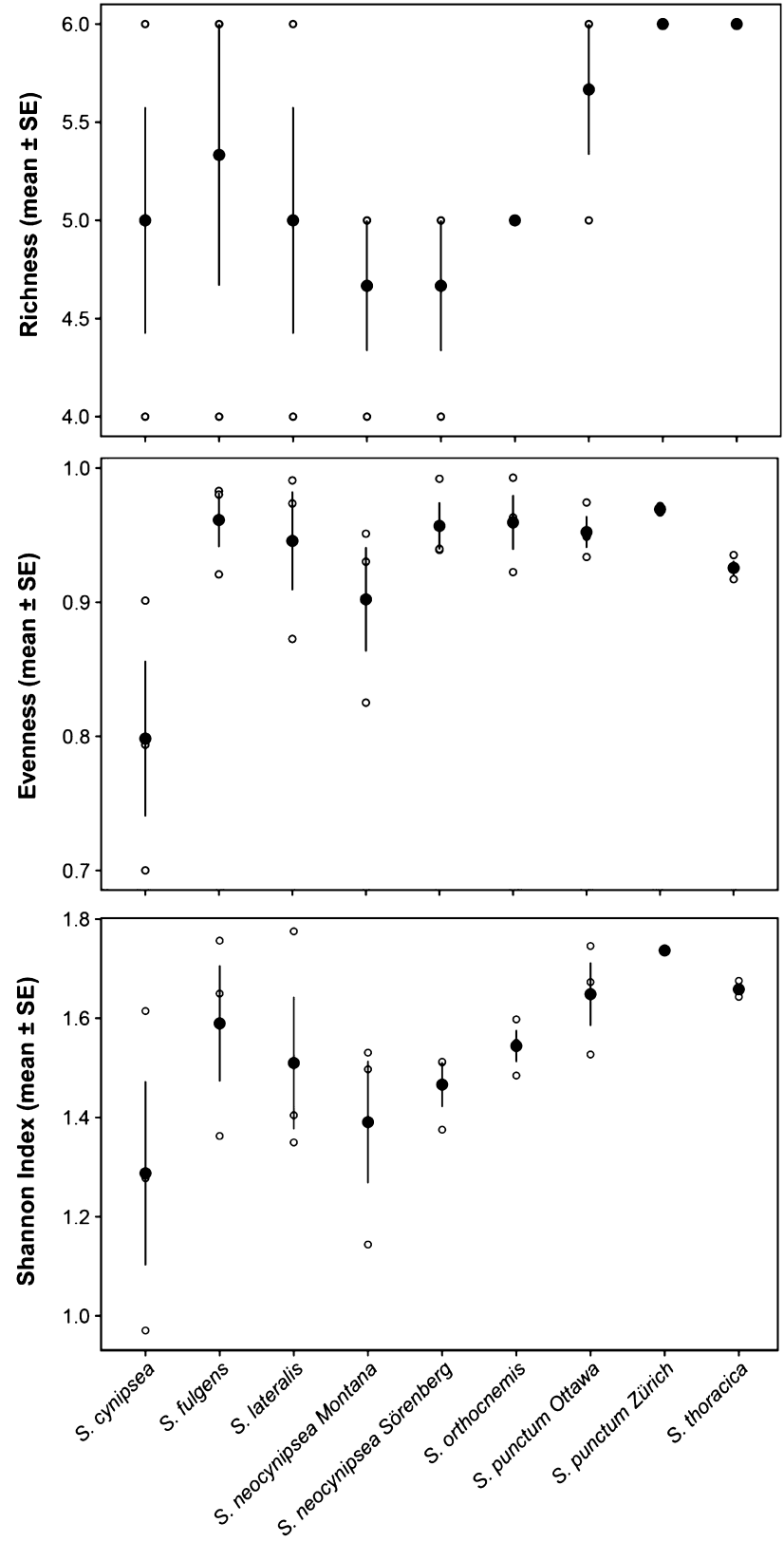

Appendix: Fig. A1. Mean (filled circles) \pm SE of various standard diversity indices indicating the degree of specialisation of 9 (sub) species of Sepsis flies for 6 types of vertebrate dung based on larval survival (i.e. Fig. 1; the range in the replicates for each species is indicated by the open circles). 